\title{
A formação do
}

professor de música

e o estágio

Melita Bona 
Neste artigo $^{3}$ apresentam-se os resultados da trajetória do Estágio Obrigatório em Música realizado por uma turma de alunos do Curso de Música da Universidade Regional de Blumenau, FURB. Compreende-se o estágio como um processo, no qual os conhecimentos e as competências adquiridas durante o curso sejam transformados em açõespedagógicas. Nestapesquisa, aponta-separaasatividadesdeestágio como possibilidade de inserção do aluno à pesquisa científica. Os dados correspondem às quatro fases do estágio desenvolvidas nos semestres letivos de 2008 e 2009, compreendendo a observação e a prática do ensino de Música na Educação Infantil, no Ensino Fundamental e no Ensino Médio. Analisam-se os relatórios obtidos ao final de cada uma das fases, no sentido de verificar se os acadêmicos deram continuidade às questões de pesquisa apresentadas no início do processo. Os resultados indicam que, na maioria dos trabalhos, o foco de pesquisa permaneceu e o caráter investigativo do estágio corroborou para práticas educativas mais elaboradas.

Palavras-chave: Ensino de música; Estágio; Pesquisa.

\section{Introdução}

Teste artigo, discute-se a formação do professor de Música a partir de 1 um estudo realizado junto a uma turma de estagiários do Curso de Música da Universidade Regional de Blumenau, FURB. Compreende-se a formação do professor e a sua competência de pesquisador como frutos de um importante processo de construção elaborado no decorrer do curso, da mesma forma que o estágio exerce um papel fundamental, o de norteador de açóes pedagógicas e condutas acadêmicas futuras.

Pressupóe-se que, além de validar as práticas educativas, o estágio possa ser, simultaneamente, uma introdução às açóes de pesquisa, dadas as semelhanças existentes entre os procedimentos - observação, coleta de dados, análise, reflexão, produçáo de relatório -, a fim de que o caráter investigativo desperte maior motivação no comportamento dos estagiários. O presente estudo, oriundo do exercício das atividades da disciplina

${ }^{3}$ Este artigo será publicado como um capítulo do livro: SCHROEDER, E.; SILVA, V.L.S. (Org.). Estágios em foco: a pesquisa, a teoria e a prática na formaçáo do professor na FURB. Blumenau: EDIFURB (no prelo). 
de Estágio Obrigatório em Música I, aponta para a possibilidade do campo de estágio como iniciação e estímulo à pesquisa, colocando em foco as práticas desenvolvidas com uma turma de alunos, durante as quatro fases da disciplina de Estágio Obrigatório em Música (I, II, III e IV), do Curso de Música da FURB, no decorrer dos períodos letivos dos anos 2008 e 2009.

Inicia-se com a descrição das circunstâncias que deram origem à investigação, sua localização no contexto da Educação e da Educação Musical. Nos tópicos seguintes, apresentam-se os procedimentos realizados, bem como a análise dos dados.

\section{Origem do Estudo}

estágio no Curso de Música da Universidade Regional de Blumenau - FURB - constitui-se de quatro fases, distribuídas em quatro semestres, sendo que a primeira fase compreende a observação da realidade escolar em todos os níveis da Educação Básica.

No primeiro semestre de 2008, a turma da quinta fase, matriculada na disciplina de Estágio Obrigatório em Música I, compunha-se de 27 alunos. Durante a explanação sobre os procedimentos e as etapas a serem cumpridas, os acadêmicos manifestaram apreensão e surgiram dúvidas em relação aos aspectos a serem observados e ao estágio em si. Pairava no ar certo desconforto a respeito do que estava sendo proposto e, com frequência, ouviam-se comentários com o seguinte teor: "Mas se não tem Música na escola, o que irei observar?".

Para a maioria deles, em decorrência, haveria o primeiro contato com um estabelecimento de ensino desde o término de sua trajetória escolar. Além disso, o estágio parecia ser algo pouco interessante e, no entender de alguns, deveria ser realizado o mais rápido possível para que estivessem 'livres' daquela situação. Motivar esses alunos para o estágio de modo que a disciplina viesse a se tornar uma experiência desafiadora foi o objetivo central a partir daquele momento. As açóes desenvolvidas com base nos questionamentos e nas inquietaçóes dos acadêmicos foram registradas e deram origem ao estudo aqui apresentado.

Nas últimas décadas, há estudos consideráveis no campo da Educação (FAZENDA, 1991; PIMENTA, 2001) que discutem a 
prática de ensino e o estágio nos cursos de licenciatura. A proposta de nortear o estágio em direção à pesquisa atende às questóes contemporâneas da formação do professor e apoia-se em normativas legais.

$\mathrm{Na}$ Universidade Regional de Blumenau - FURB, as discussões sobre o estágio nas licenciaturas como ação diagnóstica e de incentivo à pesquisa tornaram-se mais frequentes desde a aprovação do anexo do Regulamento do Estágio Curricular Obrigatório, resolução n ${ }^{\circ}$ 92/2004, de 16 de dezembro de 2004 . O artigo $3^{\circ}$, do capítulo II, do referido regulamento assegura que

O Estágio Curricular Obrigatório das Licenciaturas tem por objetivo oportunizar o confronto com os problemas concretos das questóes do processo pedagógico, por intermédio do conhecer, interpretar e agir conscientemente, além de deasenvolver a capacidade científica do estagiário, privilegiando a formação de um professor pesquisador (FURB, 2004, fls. 3).

Promover o ensino, a pesquisa e a extensão de forma integrada faz parte dos alicerces da referida Universidade.

A partir das determinaçóes da Lei de Diretrizes e Bases $n^{\circ}$ 9.394, de 1996, as reflexóes e pesquisas sobre o estágio, envolvendo a formação de professores, intensificaram-se no campo da Educação Musical (BELLOCHIO; BUCHMANN, 2007; MATEIRO; SOUZA, 2006; MATEIRO, 2006; MATEIRO; TÉO, 2003; SOARES, 2008). A relação entre a prática de estágio e a formação do professor de Música é amplamente discutida por Mateiro e Souza (2006). Segundo as autoras:

O debate sobre a prática de ensino na formação de professores é um tema que vem sendo discutido e estudado, pelo menos nos últimos 20 anos. É de comum acordo entre os profissionais da área da educação que a prática de ensino, incluindo o estágio, é um dos componentes curriculares mais importantes e valiosos dentro dos programas de formação docente (MATEIRO; SOUZA, 2006, p. 8).

Para Bellochio e Buchmann (2007), “o estágio curricular supervisionado é um componente que ocupa lugar de destaque nos cursos superiores de formação de professores" (BELLOCHIO; BUCHMANN; 2007 p. 229). 
As Diretrizes Curriculares Nacionais do Curso de Graduação em Música, aprovadas em 8 de março de 2004, no artigo $2^{\circ}$, mencionam o "incentivo à pesquisa como necessário prolongamento da atividade de ensino e como instrumento para a iniciação científica" (DCN de Música, 2004, Art. $2^{\circ}$, par. 1º, IX). No documento, o estágio compreende a integração entre a teoria e a prática.

Há autores destacados que discutem as contribuiçóes da pesquisa na formação do professor de Música (BASTIAN, 2000; MOTA, 2003; SANTOS, 1996; SOUZA, 2003). Para Mota (2003), "formar docentes investigadores parece ser o compromisso mais válido para assegurar que a formação não acabe com a entrega do diploma, mas se projecte num processo dinâmico de pesquisa continuada" (MOTA, 2003, p. 15).

Segundo Bastian,

pesquisa na graduação significa concretamente: assim como os alunos no contexto da escola, da sala de aula, reconhecem, inventam, exploram, experimentam, também o futuro professor pode 'aprender a pesquisar' ${ }^{34}$, considerando a sua prática (BASTIAN, 2000, p. 97).

\section{$\mathrm{O}$ autor prossegue:}

Não é preciso enfatizar que os estudantes também se qualificam didaticamente nas observaçóes de sala de aula, na avaliação de problemas metodológicos, no encontro e convívio com os alunos e demais propostas; que eles descobrem seus próprios problemas e seguem adiante; que conseguem chegar a questôes relevantes específicas da área que ainda não tinham adquirido anteriormente (BASTIAN, 2000, p. 98).

Assim também se considera legítima a afirmação de Santos: "a atitude de pesquisa leva à construção do conhecimento, leva à comprovação ou não de suposições (intuições), leva à substituição de falsos dogmas aclamados" (SANTOS, 1996, p. 150).

Nessa perspectiva, o estágio é um processo segundo o qual os conhecimentos e as competências adquiridas no decorrer do curso são articulados e transformados em açóes pedagógicas. 
Parte-se do pressuposto que a concatenação entre o estágio e a pesquisa seja possível, e quando ambos são realizados a partir do foco de interesse do aluno, que os resultados sejam ainda mais profícuos e que a aproximaçáo com o universo da pesquisa possa contribuir para a construção dos saberes dos professores em formação.

\section{Estágio I: A pergunta de partida}

A s inquietaçóes observadas nas primeiras aulas conduziram as A investigaçóes sobre as impressóes dos alunos em relação à escola. De acordo com o propósito de direcionar o estágio aos focos de interesse, as atividades foram iniciadas com reflexóes junto ao grupo a partir de questóes, a saber: Quais as suas angústias em relaçáo à escola? O que você gostaria de entender e investigar na escola em relação ao ensino da Música?

As respostas individuais a essas perguntas, registradas pela autora, apresentaram assuntos e questionamentos diversos relacionados à escola, mas também pontos comuns existentes na turma (vide Apêndice). Propôs-se, então, a formação de grupos, ordenados de acordo com as afinidades e que, no primeiro momento, registraram os tópicos referentes a cada uma das temáticas. Das reflexóes desses grupos surgiram cinco questóes de pesquisa que passaram a nortear as discussóes em sala de aula e as açóes no campo de estágio:

a) Formação do professor que lida com a Música na escola

Oito alunos participaram do grupo que discutiu a questão e apresentou os seguintes tópicos como critérios de observação no campo de estágio: verificar se, na escola, a Música é compreendida como conhecimento e de que modo o professor de Artes ${ }^{5}$ lida com ela. Também mencionaram interesse pela didática utilizada pelo professor. O grupo realizou o Estágio I organizado em três duplas, além de dois alunos que atuaram individualmente.

b) Repertório musical praticado na escola

O grupo que mostrou interesse por essa questão compunhase de seis alunos, os quais levantaram os seguintes questiona mentos:

${ }^{5} \mathrm{O}$ professor de Artes, na maioria dos casos, é formado em Artes Visuais. 
Qual o panorama da prática de escuta musical na escola? Como ampliar os horizontes musicais por meio do repertório? De que forma a diversidade musical é contemplada na escola? Como lidar com o repertório musical que a criança não conhece? $\mathrm{O}$ grupo realizou o Estágio I com a formação de três duplas de estagiários.

\section{c) Ensino de Música e alunos portadores de deficiências}

Constituído de seis alunos, o grupo mostrou interesse em aprofundar os conhecimentos sobre a estrutura do cérebro humano e registrou os seguintes questionamentos: Como se processa a aprendizagem musical? Como trabalhar a Música com alunos portadores de deficiências? De que modo verificar as reaçóes e as possíveis consequências da Música em suas vidas?

\section{d) Contribuiçóes da Música para a formação global do indivíduo}

O grupo interessado nessa temática, formado por cinco alunos, apontou a seguinte questão: A música tem influência sobre o comportamento do indivíduo? A partir daí, o grupo refletiu sobre as formas de conduzir a investigação durante o estágio: observar as aulas ministradas pelas educadoras na Educação Infantil e verificar quando e de que modo trabalham com a Música. No âmbito do Ensino Fundamental, comparar as turmas de alunos que têm aulas de Música com as turmas que não têm, a fim de avaliar as semelhanças e diferenças; observar atentamente as posturas e as atitudes dos professores de Música e participar de reunióes pedagógicas nas escolas para verificar de que modo a Música é incluída (ou não) e abordada na instituição.

e) Relação entre o plano de ensino de Música e o PPP da escola

Dois alunos mostraram interesse pela temática e destacaram as questóes: Quando e por quem foi escrito o PPP da escola e qual o seu embasamento? Comparando o plano de ensino do professor com o PPP, quais os referenciais da Música na jornada ampliada? E, ainda, qual a receptividade do aluno em relação ao conteúdo?

Os passos seguintes foram leituras e discussóes de textos específicos para cada grupo temático e a formação das duplas de estagiários. De modo geral, o critério de escolha e definição na formação das duplas foi a afinidade entre os alunos e o interesse no foco de pesquisa. Alinhados à sua questão de pesquisa, as duplas elaboraram os projetos e deram início às práticas no campo de estágio. 
Tabela 1 - Formação e Temáticas no Estágio I

\begin{tabular}{|l|c|c|}
\hline \multicolumn{1}{|c|}{ Questáo de pesquisa } & $\begin{array}{c}\text { Grupo } \\
\text { de } \\
\text { pesquisa }\end{array}$ & $\begin{array}{c}\text { Formaçáo } \\
\text { do Estágio I }\end{array}$ \\
\hline a Formação do professor que lida com a Música na escola & 08 & $\begin{array}{c}03 \text { duplas } \\
02 \\
\text { individuais }\end{array}$ \\
\hline b Repertório musical prático na escola & 06 & 03 duplas \\
\hline c Ensino de Música e alunos portadors de deficiências & 06 & 03 duplas \\
\hline $\begin{array}{l}\text { d Contribuiçóes da Música para a formação } \\
\text { global do indivíduo }\end{array}$ & 05 & 02 duplas \\
\hline $\begin{array}{l}\text { e Relação entre o plano de ensino de Música } \\
\text { e o PPP da escola }\end{array}$ & 02 & 01 dupla \\
\hline
\end{tabular}

Conforme já mencionado, a primeira fase do estágio tem como objetivo propiciar um contato direto com a realidade escolar. Os estagiários realizaram observaçóes nos diferentes níveis de ensino da Educação Básica: Educação Infantil, Ensino Fundamental, Ensino Médio e também em espaços alternativos. Nos estágios subsequentes (II, III e IV), as questôes de pesquisa foram retomadas. O Estágio Obrigatório em Música II ocorreu na Educação Infantil. O Estágio Obrigatório em Música III, no Ensino Fundamental. No Estágio Obrigatório em Música IV, a prática deu-se no Ensino Médio. Em cada uma das fases, os estagiários realizaram observações, dialogaram com os professores e coordenadores das instituiçôes, atuaram em sala de aula, organizaram um seminário sobre as experiências de estágio e finalizaram com a entrega do relatório. De acordo com Bastian,

Orientação na "ciência e pesquisa" não se considera somente a execução material da produção científica, mas também e justamente aí, o aspecto formal no processo, procedimento e atitude do conhecimento científico que se transforma em qualidade didática como "aprender pesquisando" ou "pensamento voltado para a sistematização e resolução de problemas" (BASTIAN, 2000, p. 98) [grifos do autor].

A permanência nas questóes de pesquisa não foi uma exigência. A opção ou habilidade de adequar as atividades de estágio ao foco de interesse inicial ficou a critério dos alunos. 


\section{Estágios II, III e IV: dados e análise}

Wa primeira fase do estágio, havia 27 alunos organizados em 1 onze duplas, sendo que cinco alunos realizaram o estágio individualmente, dos quais um não concluiuo semestre. Asegundafase de estágio compunha-se de 22 alunos que constituíram onze duplas, das quais nove permaneceram na mesma formação do estágio anterior. $\mathrm{Na}$ terceira fase, os 24 estagiários formaram doze duplas, e nove duplas mantiveram a formação original. No último estágio, os 26 alunos se organizaram em treze duplas, entre as quais nove mantiveram a composição inicial.

Tabela 2 - Formação das duplas durante as quatro fases de estágio

\begin{tabular}{|l|c|c|c|c|}
\hline \multicolumn{1}{|c|}{ Fases de estágio } & I & II & III & IV \\
\hline Alunos inscritos & 27 & 22 & 24 & 28 \\
\hline Formaçóes / Duplas & $11(5$ ind $)$ & 11 & 12 & 13 \\
\hline Duplas estáveis nas quatro fases & - & 09 & 09 & 09 \\
\hline
\end{tabular}

Assim o foco desta análise são as nove duplas de alunos que realizaram suas pesquisas nos estágios I, II, III e IV na mesma formação, uma vez que a estabilidade da dupla foi determinante para a verificação do processo de permanência nas questóes de pesquisa. Por motivos éticos, apresentam-se apenas as iniciais dos nomes dos estagiários.

Além das observações realizadas durante as práticas educativas dos estagiários, os relatórios apresentados nas quatro fases do estágio foram comparados, utilizando-se como critérios de análise: o foco de interesse e de pesquisa inicial, os títulos dos relatórios e as mençóes em relaçáo ao foco de pesquisa no decorrer do texto.

Das nove duplas analisadas, quatro dáo continuidade ao foco de interesse apresentado no Estágio I, durante as quatro fases de estágio.

Os alunos CM e MK têm como questão de pesquisa o item (b) repertório musical praticado na escola. Os títulos dos relatórios são indícios da permanência no tema. No Estágio I, com o relatório "Diversidade cultural no repertório das aulas de música", os estagiários investigam a forma de atuação dos professores no ensino básico 
diante da diversidade de gêneros e movimentos culturais contemporâneos presentes na escola. Em suas consideraçóes, pontuam que não tiveram oportunidade de observar aulas de Música durante essa fase de estágio, pois, nas instituiçoóes visitadas, essa disciplina não estava presente de forma regular. Tal fato reduziu as possibilidades da intenção de análise inicial. Ocorreu, então, o direcionamento da observação para outras linguagens artísticas e veio à tona uma questão para nortear a continuidade da pesquisa: "O professor de Artes tem consciência de seu papel e dever na ampliação do universo cultural de seus alunos?".

No relatório do Estágio II, "Musicalizando a partir de cantigas e brincadeiras de roda brasileiras", os acadêmicos mencionam que não encontraram respostas para seus questionamentos, pois observaram poucas aulas de Música e, ainda assim, com poucos exemplos de repertório musical. Deixam claro que faltou tempo para um levantamento de dados mais aprimorado e afirmam: "Pretendemos continuar a pesquisa nos semestres posteriores (...)". Ao discorrerem sobre a ausência de aulas de Música na escola, dizem: "A Música é deixada de lado".

$\mathrm{Na}$ introdução do relatório da terceira fase de estágio, "Corpo e Movimento: uma maneira de descobrir a diversidade cultural", os alunos fazem menção aos estágios anteriores e ao foco principal, "as diversas heranças culturais que convivem na população brasileira (...)”.

No relatório final do Estágio IV, "Ouvir e criar paisagens sonoras: experimentaçóes de uma classe de ensino médio", os alunos reportam-se aos estágios anteriores para discutir a temática. É possível dizer que as questóes de repertório estão presentes em todas as fases de estágio dessa dupla.

JS e SM também abordam a questão de pesquisa (b) repertório musical praticado na escola. No Estágio I, apresentam o relatório intitulado "Reflexóes sobre o ensino de Música na escola", com o qual dão início à temática. Durante o Estágio II, tiveram como foco a questão da escuta musical e comentam nas consideraçóes do seu relatório:

A importância que demos à audiçáo musical nesta prática de estágio está intimamente ligada ao nosso foco de pesquisa. Propiciar uma apreciação musical consciente foi a maneira que encontramos de chegar mais perto do gosto musical, foco de pesquisa que pretendemos seguir até o final da graduação. (Reflexôes sobre a prática da apreciação musical na Educação Infantil. JS e SM, Relatório do Estágio II) 
$\mathrm{Na}$ terceira fase do Estágio, a prática foi realizada com uma $4^{\mathrm{a}}$ série e uma $7^{\mathrm{a}}$ série do Ensino Fundamental. Os estagiários objetivam compreender as relações que se estabelecem entre os alunos e o repertório musical. O relatório final intitula-se "Música na Escola: as relações entre aluno e repertório". Aqui se percebe que eles também persistem na temática no Estágio IV, realizado no Ensino Médio. Na introdução do relatório final, "Analisando a influência da mídia e de fatores externos nas preferências musicais do adolescente", há uma retrospectiva do processo vivenciado durante a trajetória da pesquisa.

Destaca-se que essa dupla de alunos deu continuidade ao trabalho após o término do curso de Música, com a publicação de um artigo (MONDINI; SILVEIRA, 2010) no qual discutem a influência da mídia e de outros fatores nas escolhas do repertório e na formação do gosto musical do adolescente. Sobre o processo desenvolvido no decorrer do estágio, eles declaram: "Esta conexão entre todos os estágios realizados durante a graduação somente é possível porque mantivemos a linha de pesquisa adaptando as práticas para cada faixa etária" (MONDINI; SILVEIRA, 2010, p. 1). De acordo com essa perspectiva, Souza afirma que:

Se pesquisa é sempre concebida para melhorar a prática, ou seja, se ela existe para melhorar a prática, a pesquisa em educação musical deve não só se preocupar com o acúmulo de conhecimentos, mas também com a sua praticidade e valor para a didática da música (SOUZA, 2003, p. 9).

A dupla GB e TM teve como foco o item (d) contribuiçóes da Música para a formação global do indivíduo. Em todas as fases do estágio, nortearam-se pela pergunta: "Qual a influência da Música na formação crítica do indivíduo?".

No relatório do Estágio I, "A Música e a Formação Crítica”, os alunos admitem que se desviaram do foco, tendo em vista que a Música, em todas as instâncias, é considerada uma ferramenta funcional, mas não observaram aulas de Música propriamente ditas. Em suas consideraçóes, apontam para a ausência da apreciação musical e da Música como área de conhecimento.

No Estágio II, o relatório da dupla, "Análise do andamento musical no comportamento da criança", retoma a pergunta inicial: 
"Qual a influência da Música na formação crítica no indivíduo?”. Os estagiários finalizam o relatório dizendo que, de acordo com os objetivos propostos, obtiveram um resultado considerável no que diz respeito ao comportamento e ao entendimento das crianças sobre o andamento musical em relação às noçóes de tempo e de espaço.

A prática do Estágio III foi realizada em uma turma do $5^{\circ}$ ano e outra no $8^{\circ}$ ano do Ensino Fundamental e igualmente norteada pela pergunta inicial, porém com tópicos específicos, de acordo com cada turma. No $5^{\circ}$ ano, o tópico trabalhado foi "Cultura de Santa Catarina"; já no $8^{\circ}$ ano, os estagiários abordaram o tópico "Música e Sociedade". Em seu relatório "Música e contribuições socioculturais: experiência de estágio", os alunos comentam: "O título de nossas práticas no $8^{\circ}$ ano, Música e Sociedade, teve por objetivo principal alcançar os adolescentes no que diz respeito aos temas que se aproximam da realidade e verbalização dos mesmos”.

$\mathrm{Na}$ quarta e última fase de estágio, a dupla intitula o relatório de "Gêneros musicais em uma turma de Ensino Médio" e continua discutindo as questôes referentes à pergunta inicial.

Os estagiários MP e MJ também desenvolveram a questão (d) contribuiçốes da Música para a formação global do indivíduo e pontuam em seus relatos: "A presente pesquisa desenvolve-se a partir de questionamentos em torno da influência da Música e da forma como o ensino desta ocorre na formação do ser humano".

Os relatórios dos Estágios I e II apresentam o mesmo título, "Música na escola: o horizonte musical na vivência do indivíduo". $\mathrm{Na}$ introdução do relatório de Estágio II, fica claro que a temática deverá permanecer como pano de fundo em todo o processo de estágio. No Estágio III, realizado no Ensino Fundamental, a dupla focalizou a exploraçáo sonora a partir de cantigas de roda, os improvisos corpóreo-instrumentais e a sensibilização aos aspectos subjetivos da Música. Na introdução do relatório de estágio da terceira fase, "Vivências musicais no ensino fundamental: exploração da paisagem sonora", os alunos afirmam: "A presente pesquisa desenvolve-se a partir do fazer musical como precursor de toda e qualquer teoria". O relatório "Música na escola: Vivências musicais e experiências sonoras" corresponde à quarta fase. Nele, os alunos se referem ao estágio como um todo, mencionando o processo de pesquisa.

$\mathrm{Na}$ análise das trajetórias das quatro duplas acima relaciona- 
das, verifica-se que duas estão relacionados à questão (b) repertório musical praticado na escola - e duas à questão (d) contribuiçóes da música para a formação global do indivíduo. Nesses trabalhos, a condução dos estágios vinculada ao foco de pesquisa fica evidente, e em três casos a intenção de permanecer na temática escolhida foi expressa pelos estagiários nos primeiros relatórios.

Considera-se que houve avanços e aprofundamentos dos focos desenvolvidos pelas duplas durante todo o processo de estágio. Segundo Souza,

a pesquisa é um elemento fundamental para uma reflexão teórico-prática, contribuindo para o desenvolvimento da observação de situações pedagógicas, preparação e estruturação da coerência da fala e para o hábito de registrar práticas (SOUZA, 2003, p. 9).

Outras quatro duplas mantiveram a formação inicial, porém apresentaram mudanças na questão de pesquisa, incluindo novas temáticas durante a realização das quatro fases de estágio.

CG e GC iniciam o Estágio I a partir da (e) relação entre o plano de ensino de Música e o PPP da escola. O relatório de estágio apresentado ao final da primeira fase, "As açóes do professor em sala de aula no dia a dia educacional", discute a relação que o professor estabelece entre o plano de ensino de Música e o PPP da escola. $\mathrm{Na}$ fase seguinte, direcionam o foco para o item (a) formação do professor que lida com a Música na escola, e o relatório intitula-se "Os procedimentos de um professor de musicalização em um CEI”.

$\mathrm{Na}$ terceira e na quarta fase do estágio, a dupla se concentra na questão (b) repertório musical praticado na escola. $\mathrm{Na}$ introduçáo do relatório do Estágio III, "Como ouvir e entender Música na escola: uma ampliação de sentidos e capacidades sonoras inseridas no campo das artes", os estagiários comentam: " $\mathrm{Na} 8$ a série, nosso objetivo era apresentar diferentes estilos musicais, de modo a trabalhar com o cotidiano dos alunos, expandindo-o, para que assim eles criassem maior afeição pela Música (...)”.

Os mesmos alunos fazem uma reflexão sobre o estágio em suas consideraçôes: "As aulas nos proporcionaram uma grande noção das inusitadas situações que podem ocorrer quando se está na posição de educador, esta classe não tão valorizada, mas de suma importância para a formação de uma sociedade." "O Universo da Música Popular 
Contemporânea: sua influência histórica e social no cotidiano da educação" é o título do relatório do Estágio IV, apresentado por essa dupla, apontando para o foco mencionado.

MC e JR têm como ponto de partida a (a) formação do professor que lida com a Música na escola, também lembrada no título do primeiro relatório de estágio, "Formação de professores: sua importância na prática de ensino em Artes". No segundo e no terceiro estágio, o foco se encontra no item (d) contribuiçôes da Música para a formação global do indivíduo. No relatório do Estágio II, "O Desenvolvimento da percepção Auditiva na Educação Infantil”, os alunos dizem que o foco anterior não se adequaria à realidade do campo de estágio. No relatório da terceira fase, "Inserindo a escola no universo musical", dão continuidade a essa discussão. O relatório final do Estágio IV apresenta uma retrospectiva dos estágios realizados nas quatro fases, discorrendo sobre a questão de pesquisa.

AR e RG iniciam o estágio com a questão (d) contribuições da Música para a formação global do indivíduo, e o relatório se intitula "Música na escola". Na segunda fase, a dupla se afasta das questóes iniciais de pesquisa e direciona sua prática de estágio para os instrumentos musicais, conforme o relatório "Instrumentos Musicais". Em sua discussão, surge uma pergunta central: "Como os instrumentos musicais podem ser apresentados às crianças de cinco e seis anos sem torná-los um assunto complexo?". Nas fases seguintes, Estágios III e IV,optam pela temática "Música Catarinense como objeto didático". No relatório da terceira fase, "A Cultura Catarinense por meio da música local: práticas no ensino fundamental", abrem a discussão sobre a importância da valorização da música local, cuja continuidade se verifica no relatório do Estágio IV, "Identidade Cultural".

JP e TR abordam a questão (c) ensino de Música e alunos portadores de deficiências - em seu relatório "A Influência da Música na Formação das Crianças”, apresentado ao final do Estágio I. Na segunda fase do estágio, retomam o tema, mantêm o mesmo titulo no relatório e mencionam as contribuiçóes da Música para o portador de deficiência. No Estágio III, abordam as "Atividades Rítmicas", porque, até aquele momento, não haviam encontrado nenhuma criança portadora de deficiência nas salas de aula durante a prática de estágio. $\mathrm{Na}$ quarta fase, trabalham com o tema "Instrumentos Musicais". 
Tabela 3 - Temática das duplas a cada semestre

\begin{tabular}{|l|c|c|c|c|}
\hline \multicolumn{1}{|c|}{ Semestre } & I & II & III & IV \\
\hline CG e GC & (e) & (a) & (a) & (b) \\
\hline MC e JR & (a) & (d) & (d) & (b) \\
\hline AR e RG & (d) & $\begin{array}{c}\text { Instrumentos } \\
\text { musicais }\end{array}$ & $\begin{array}{c}\text { Música } \\
\text { catarinense }\end{array}$ & $\begin{array}{c}\text { Música } \\
\text { catarinense }\end{array}$ \\
\hline JP e TR & (c) & (c) & $\begin{array}{c}\text { Atividades } \\
\text { rítmicas }\end{array}$ & $\begin{array}{c}\text { Instrumentos } \\
\text { musicais }\end{array}$ \\
\hline
\end{tabular}

Apesar das mudanças de temática, observou-se o envolvimento dos estagiários nas atividades, bem como o aprofundamento nas diferentes questóes. Sobre o processo inicial de pesquisa, Bastian assevera que "somente iniciando com pequenos trabalhos e projetos de pesquisa na aprendizagem, será possível chegar ao desenvolvimento de pesquisas inovadoras" (BASTIAN, 2000, p. 98).

Apenas uma dupla de estagiários não se refere ao foco de pesquisa. ER e PL inicialmente mostraram interesse pela questáo (a) formação do professor que lida com a Música na escola, porém, em seus relatórios, não há discussão sobre a questão de pesquisa.

\section{Algumas considerações}

$\mathrm{O}$ $s$ resultados obtidos na investigação sobre a trajetória dos estágios da referida turma do Curso de Música indicam que a maioria das duplas de alunos deu continuidade à questão de pesquisa apresentada no início do processo. Nesse sentido, a manutençáo das mesmas duplas foi um critério fundamental para a análise. A organização dos grupos a partir dos interesses e das interrogaçóes dos próprios alunos evidencia-se como fator determinante. Foi possível observar o envolvimento dos estagiários nas reflexôes iniciais e também o aprofundamento nas diferentes questóes, além da significativa contribuição para práticas educativas mais elaboradas.

De modo geral, os alunos mostraram-se motivados durante o estágio, pois, para a maioria, até então, o contato com o processo de pesquisa havia sido mais teórico, e a prática em sala de aula alinhada à atitude investigativa possibilitou a aproximação salutar com os autênticos procedimentos do caráter da pesquisa. 
A junção do foco de interesse de cada dupla e da prática em sala de aula nem sempre se apresentou de maneira direta e simples. Trabalhar com a curiosidade e com o contexto do aluno implica ouvi-lo, e mais ainda, dar ouvidos e voz às suas dúvidas e aos questionamentos, o que exige flexibilidade por parte do professor orientador.

A experiência de realizar o estágio nos moldes aqui descritos apresentou resultados animadores: quatro das nove duplas de alunos analisadas permaneceram no foco de interesse e de pesquisa selecionado no início do estágio, outras quatro duplas apresentaram mudanças de foco no decorrer do processo de estágio e uma dupla não mencionou o foco de investigação em nenhum dos relatórios.

Frente às novidades no que diz respeito à Música em sala de aula, especialmente com a aprovaçáo da Lei 11.769, de 18 de agosto de 2008, que regulamenta a sua inclusão na grade curricular do Ensino Básico, as discussóes em torno da formação do professor especialista se intensificaram. A aprovação da referida Lei foi uma conquista, porém ela, por si só, não garante a execução da tarefa. Diversos esforços serão necessários para que a Lei se concretize. Sem dúvida, uma empreitada a longo prazo a ser cumprida.

Artigos e entrevistas recentemente veiculados pela mídia, abordando a qualidade da Educação brasileira, enfatizam a necessidade de reflexão sobre o tipo de professor que estamos formando nos cursos de licenciatura. Sob essa óptica, entende-se o estágio como um dos componentes curriculares de maior peso nesses cursos e, consequentemente, naformaçãodoprofessor. Ocontato comosdiferentes contextos do campo da Educação, o exercício de observar, de conhecer e de agir em sala de aula permitem ao estagiário estabelecer relaçóes entre suas hipóteses, a realidade e a teoria.

No estudo, verifica-se que, para alguns, a identificação com o campo da Educação emerge durante o processo de estágio, afinal, o reconhecer-se como futuro professor, o querer (ou náo) dar seguimento à atividade acadêmica clareia-se no exercício da prática.

A realização do estágio orientado para a investigação e a partir das inquietaçóes dos alunos pode ser um estímulo à iniciação ao universo da pesquisa e à formação de um olhar crítico e mais instigante sobre as ações pedagógicas do futuro professor de Música. 


\section{Referências}

BASTIAN, Hans G. A pesquisa (empírica) na educação musical à luz do pragmatismo. In: Em Pauta. Revista do Curso de Pós Graduação Mestrado em Música; UFRGS, v.11, n.16/17 - abr/nov 2000, p. 77-106.

BELlOCHIO, Claudia R.; BUCHMANN, Letícia T. O Estágio Supervisionado em Música: Um estudo na UFSM. In: Encontro Regional da ABEM Sul, 10, 2007, Blumenau, Anais..., Blumenau: ABEM 2007, p. 229-235, CD-ROM.

BONA, Melita. O estágio supervisionado em música na perspectiva da iniciação à pesquisa. In: Congresso Nacional da ABEM, 18, 2009, Anais... , Londrina: ABEM, 2009, CD-ROM.

- Estágio supervisionado e a formação do professor pesquisador. In: Encontro Regional da ABEM Sul, 13, 2010, Anais... , Porto Alegre: Editora Universitária Metodista IPA, 2010.

- Música na Escola: reflexóes sobre a prática musical na sala de aula. In: III Simpósio Catarinense de Educação Musical, 2011, Anais... , Jaraguá do Sul: VI FEMUSC- Festival de Música de Santa Catarina, 2011.

FAZENDA, Ivani C. A. O papel do estágio nos cursos de formação de professores. In: FAZENDA, Ivani C. A. et al. PICONEZ, Stela C. B. (coord.). A prática de ensino e o estágio supervisionado. Campinas: Papirus, 1991, p. 53-62.

FURB - Universidade Regional de Blumenau. Resolução $N^{\circ}$ 92/2004: Aprovaçáo do Regulamento do Estágio Curricular Obrigatório dos Cursos de Licenciatura da Universidade Regional de Blumenau, na forma de anexo. $16 \operatorname{dez} 2004$, folha 3 .

MATEIRO, Teresa; SOUZA, Jusamara. (Org.) Práticas de ensinar música: legislação, planejamento, observação, registro, orientação espaços e formação. Porto Alegre: Sulina, 2006. 
MATEIRO, Teresa. A prática de ensino na formação dos professores de música: aspectos da legislação brasileira. In: MATEIRO, Teresa; SOUZA, Jusamara. (Org.) Práticas de ensinar música: legislação, planejamento, observação, registro, orientação espaços e formação. Porto Alegre: Sulina, 2006, p. 15-27.

MATEIRO, Teresa; TÉO, Marcelo. Os relatórios de estágio dos alunos de música como instrumento de análise dos processos de planejamento. Revista da ABEM, Porto Alegre, v. 9, set 2003, p. 89-95.

MONDINI, Suelen J. H.; SILVEIRA, Jurian G. S. A influência da mídia e de fatores externos nas preferências musicais do adolescente. In: Encontro Regional da ABEM Sul, 13, 2010, Anais... , Porto Alegre: Editora Universitária Metodista IPA, 2010.

MOTA, Graça. Pesquisa e formação em educação musical. In: Revista da $A B E M, \mathrm{n} .8$, Porto Alegre: Associação Brasileira de Educação Musical, mar 2003, p. 11-16.

PIMENTA, Selma G. O Estágio na Formação de Professores: Unidade Teoria e Prática? 4a ed. São Paulo: Cortez, 2001.

SANTOS, Regina M. S. A pesquisa no ensino da Música. In: Encontro Anual da Associação Brasileira de Educação Musical / $5^{\circ}$ Simpósio Paranaense de Educação Musical. Londrina: ABEM, 1996, p. 145-169.

SOARES, José. Estágio Supervisionado: experiências de 11 alunos do curso de licenciatura em música da Universidade do Estado de Santa Catarina. Florianópolis. In: Encontro Nacional da ABEM, 17, 2008, São Paulo, Anais..., São Paulo: ABEM 2008, CD-ROM.

SOUZA, Jusamara. Pesquisa e Formação em Educação Musical. In: Revista da $A B E M$, n. 8, Porto Alegre: Associaçáo Brasileira de Educação Musical, mar 2003, p. 7-10. 


\section{Apêndice A}

Respostas às questôes: Quais as suas angústias em relação à escola? O que você gostaria de entender e investigar na escola emrelação ao ensino da Música? (março de 2008).

1. A importância que o professor de Artes atribui à aula de Música (PT).

2. De que maneira a Música pode influenciar no comportamento e na socialização dos alunos (TM).

3. Quais os pressupostos que o professor deve ter para dar aula de Música (GB).

4. De que forma a Música contribui na formação do indivíduo (MJ).

5. Como desenvolver a criatividade musical e ampliar os horizontes dos alunos (MP).

6. De que forma é ensinada a diversidade musical na escola (CM).

7. Como lidar com a Música que a criança não conhece (MK).

8. De que forma a Música é trabalhada pelo professor de Artes Visuais (MB).

9. Como o professor de Artes Visuais lida com a Música (F).

10. O que fazer para que haja musicalização na escola (PL).

11. Porque há poucos professores de Artes nos cargos de chefia. Como se processa a aprendizagem musical sob a perspectiva da neurociência (AT).

12. De que modo a Música influencia na questão comportamental do indivíduo (LE).

13. Verificar como está a questão musical na jornada ampliada (MS).

14. A valorização da Música como objeto de conhecimento (GC).

15. A relaçáa do PPP da escola com a ação do professor que lida com a Música. A ampliação do repertório musical (CG).

16. Como trabalhar a Música com as crianças deficientes auditivas (TR).

17. Contribuiçôes da Música para o deficiente (JP).

18. Perfil da escuta de Música na escola (SM).

19. De que forma trabalhar a Música como arte sem interferir no gosto (JS). 
20. As questôes didáticas e os planos de aula do professor de Artes (ER).

21. Como lidar com as crianças deficientes (CF).

22. Quais os conteúdos trabalhados pelo professor de Artes (RG).

23. O que eu devo fazer na aula de Música $(\mathrm{JH})$.

24. Qual o objetivo da aula de Música na escola. Como abordar os diversos gêneros musicais e repertórios $(\mathrm{PH})$.

25. O conteúdo musical abordado pelo professor especialista e o desenvolvimento desse conteúdo (JR).

26. Os planejamentos na área de Música (MC).

27. Aspectos históricos no ensino de Música tendo como coadjuvante os conhecimentos da neurociência (AR). 